\title{
Hyponatraemic encephalopathy induced by single dose Indapamide
}

\section{Haya N \& Noordally K \\ East Sussex NHS Trust}

\section{Introduction}

Hyponatraemia, defined as a serum $\left[\mathrm{Na}^{+}\right]<135 \mathrm{mmol} /$, is the most common of electrolyte abnormalities, both in the community and in the hospital setting, (seen in $2 \%$ of hospital patients, and up to $30 \%$ elderly patients in a nursing homes). There are numerous factors which may directly cause or contribute to hyponatraemia, including dehydration, concomitant cardiac/hepatic/renal disease, and certain medications, such as diuretics. It may cause a range of symptoms, depending on the speed and severity of the deficiency. With mild hyponatraemia, $(>115 \mathrm{mmol} / \mathrm{l})$, patients may experience malaise - nausea, vomiting and generalised fatigue. Clinically significant hyponatraemia, $\left[\mathrm{Na}^{+}\right]<115 \mathrm{mmol} / /$, manifests itself through neurological symptoms: confusion, seizures, and ultimately coma. Chronic, 'asymptomatic ' hyponatraemia has been shown extensively to cause gait disturbances, falls and neurocognitive impairment.

\section{The case of Ms. $\mathrm{H}$}

A 76 year-old lady was brought into A\&E, having been found collapsed at home. On admission, GCS was 6/15. She remained quite confused, agitated and disorientated whilst in resus. She was euvolaemic, with an adequate cardiac output, and normal blood glucose. CT-head showed no acute intracranial abnormality to account for her presentation. Laboratory work up showed a profound hyponatraemia, $\left[\mathrm{Na}^{+}\right]=108$. Prior to this admission, her sodium levels were within normal ranges

Her past medical history also included asthma, ischaemic heart disease, and well-managed hypothyroidism. She had been a lifelong smoker, although she denied any new respiratory symptoms, or weight loss. She reported having commenced indapamide for hypertension one day prior to presentation.

\section{Conclusion \\ Ultimately, the management of hyponatraemia requires identification and appropriate management of the underlying cause. Commonly, patients with hyponatraemia secondary to SIADH are placed on a fluid restriction. Patients who present acutely in extremis with hyponatraemia (neurological symptoms) should receive hypertonic saline infusion. It is vital that $\left[\mathrm{Na}^{+}\right]$is not corrected too quickly, (no more than an increase of $8-12 \mathrm{mmol} / \mathrm{L}$ over 24 hours) to prevent central pontine myelinolysis, (CPM), and subsequent permanent neurological dysfunction.}

Diuretics are commonly associated with hyponatraemia, as well as other electrolyte abnormalities. However this is the first reported case of clinically significan hyponatraemia following single dose of indapamide. Hyponatraemia may lead to an encephalopathic state, and as such, these side-effects should always be considered prior to commencing this medication.

\section{Laboratory work}

On admission: $\mathrm{K}=4.2 \mathrm{mmol} / \mathrm{l}$; corrected calcium $=2.13 \mathrm{mmol} / \mathrm{l}$. She was hyperphosphataemic $\left(\mathrm{PO}_{4}=1.67 \mathrm{mmol} / \mathrm{l}\right)$, hypercholesterolaemic $(7.1 \mathrm{mmol} / \mathrm{I})$, with subclinical hypothyroidism $(\mathrm{TSH}=9.9 \mathrm{mU} / \mathrm{l}$, free $\mathrm{T} 4=18 \mathrm{pmol} / \mathrm{l})$. Her urinary osmolality was $475 \mathrm{mOsm} / \mathrm{kg}$; urinary $\left[\mathrm{Na}^{+}\right]$was 27 ; serum osmolality, 236 . Her serum cortisol was $761 \mathrm{nmol} / /$. Moreover she had abnormal dexamethasonesuppression test, together with an elevated 25-urinary free cortisol. The rest of her biochemistry profile, including liver function tests, were unremarkable.

\section{Management}

She was put onto fluid restriction, with a strict input/output chart. Indapamide was stopped. She had regular $\left[\mathrm{Na}^{+}\right]$checks, which showed gradual improvement in the hyponatraemia: $108 \mathrm{mmol} / /$ on admission, $111 \mathrm{mmol} / /$ the following day, $120 \mathrm{mmol} / \mathrm{l}$ the next, $127 \mathrm{mmol} / \mathrm{l}$ the next.

She was notably less confused and agitated on discharge, and, when reviewed in clinic a few weeks later, her symptoms had resolved entirely. More recent biochemistry shows a stable and normal sodium $[\mathrm{Na}=126 \mathrm{mmol} / 1]$. Upon discharge, the patient complied with a full-body CT scan, which showed no paraneoplastic cause for her hyponatrameia. The most recent blood test shows $\left[\mathrm{Na}^{+}\right]=134 \mathrm{mmol} / \mathrm{l}$

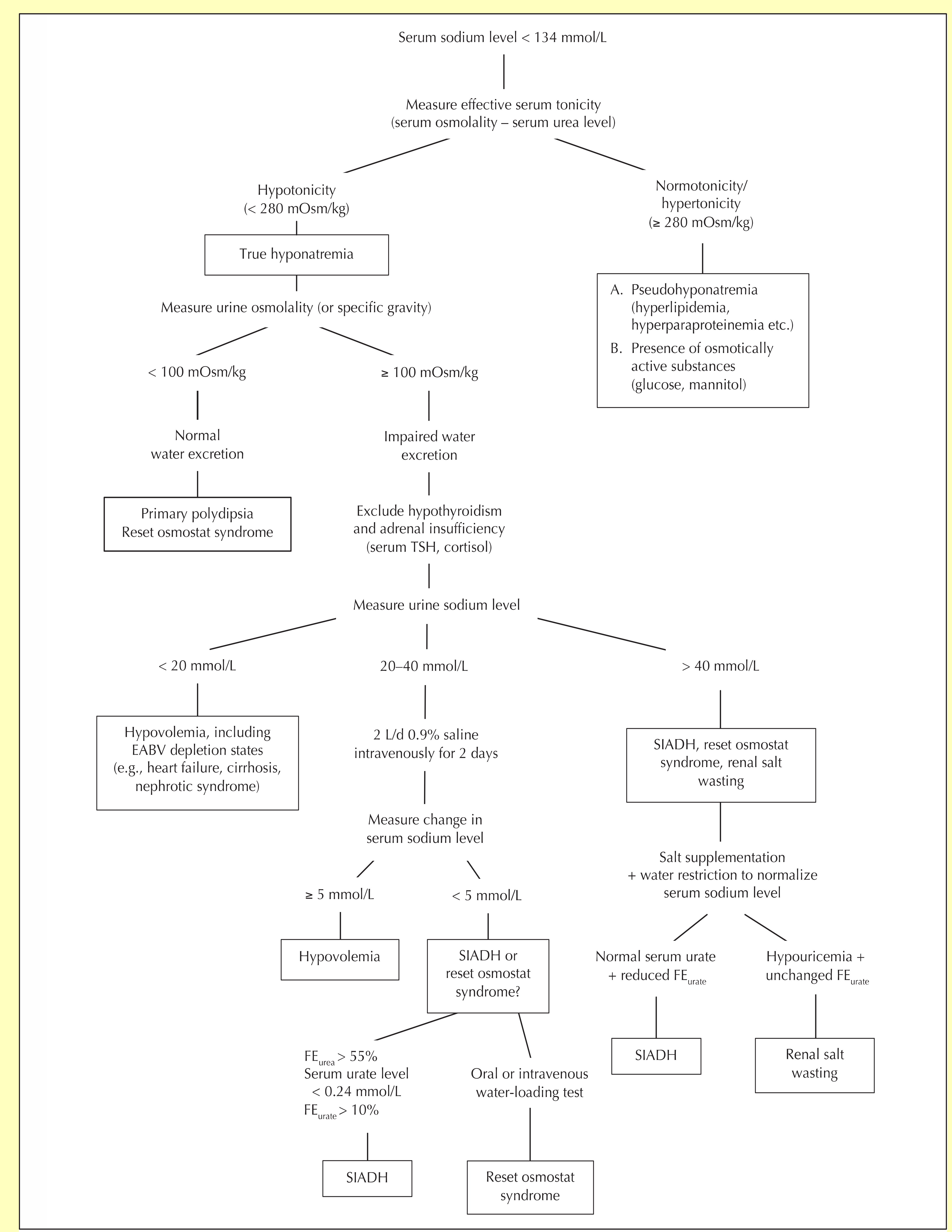

Clinical algorithm for evaluation of hyponatraemia: TSH - thyroid stimulating hormone; EABV-effective arterial blood volume; SIADH - syndrome of inappropriate ADH release; FE - fractional excretion 